\title{
Ultralow Wear Perfluoroalkoxy (PFA) and Alumina Composites
}

Mark A. Sidebottom ${ }^{1}$, Angela A. Pitenis ${ }^{2}$, Christopher P. Junk ${ }^{3,4}$, Daniel J. Kasprzak ${ }^{4}$, Gregory S. Blackman ${ }^{4}$, Heidi E. Burch ${ }^{4}$, Kathryn L. Harris ${ }^{5}$, W. Gregory Sawyer ${ }^{2,5}$, and Brandon A. Krick ${ }^{1}$

${ }^{1}$ Department of Mechanical Engineering and Mechanics

Lehigh University

Bethlehem, PA 18015

${ }^{2}$ Department of Mechanical and Aerospace Engineering

University of Florida

Gainesville, FL 32611

${ }^{3}$ Department of Material Science and Engineering

Lehigh University

Bethlehem, PA 18015

${ }^{4}$ DuPont Central Research and Development

200 Powder Mill Road, PO Box 8352

Wilmington, DE 19803

${ }^{5}$ Department of Materials Science and Engineering

University of Florida

Gainesville, FL 32611

\begin{abstract}
:
Fluoropolymers have unique mechanical, chemical, and tribological properties (low friction coefficients) but their use as solid lubricants is inhibited by high wear rates $\left(1-5 \times 10^{-4} \mathrm{~mm}^{3} / \mathrm{Nm}\right)$. The addition of certain types of $\alpha$-alumina has been shown to reduce the wear rate of PTFE by over three orders of magnitude, but due to its extremely high molecular weight PTFE cannot be screw injection molded. However, PFA, a perfluorinated copolymer of tetrafluoroethylene (TFE) and a perfluorinated alkylvinyl ether (PAVE), can be. Teflon ${ }^{\circledR}$ PFA 340 samples with various weight fractions of $\alpha$-alumina $(0 \%, 5 \%, 7.5 \%, 10 \%)$ were injection molded, and samples from each mold were wear tested against stainless steel $(\mathrm{P}=6.3 \mathrm{MPa}, \mathrm{v}=50.8 \mathrm{~mm} / \mathrm{s})$. Experiments showed that the friction behavior of the PFA 340- $\alpha$ alumina composite was very close to that of both unfilled PFA 340 and PTFE- $\alpha$ alumina composites. The wear rate of unfilled PFA 340 was $1.4 \times 10^{-4} \mathrm{~mm}^{3} / \mathrm{Nm}$, and dropped to $4.0 \times 10^{-8} \mathrm{~mm}^{3} / \mathrm{Nm}$ for the PFA- $\alpha$ alumina composites. Just as in the case of PTFE- $\alpha$ alumina composites, these PFA composites generated brown-colored tribofilms on both the polymer and metal surfaces, which were indicative of tribochemical changes. ATR-IR and FTIR spectra of each surface showed evidence for the generation of perfluorinated carboxylate salts and waters of hydration. This spectral similarity between PTFE and PFA 340 samples shows that the same tribological mechanism found in PTFE- $\alpha$ alumina composites is responsible for ultralow wear in PFA- $\alpha$ alumina composites as well.
\end{abstract}

page 1

(C) 2016. This manuscript version is made available under the Elsevier user license http://www.elsevier.com/open-access/userlicense/1.0/ 


\section{Keywords}

Friction, Wear, Fluoropolymers, PFA, PTFE, Alumina, Solid Lubricant, Polymer Composite, Screw Injection Molding, FTIR.

\section{Corresponding Author}

Brandon A. Krick

Department of Mechanical Engineering and Mechanics

Lehigh University

Bethlehem, PA 18015

phone: (610) 758-5772

fax: (610) 758-6224

email: bakrick@lehigh.edu 


\section{Introduction}

The tribological properties of PTFE have been of interest for over 50 years due to its unique thermal, chemical and mechanical properties. PTFE is a well-recognized tribological material, commonly used in unlubricated journal bearings [1,2], that is known for its very low friction coefficient yet unacceptably high wear rate [3-6]. In the past decade, the wear rate of PTFE has been reduced by 1,000 to 10,000 times with the inclusion of $1-10$ wt. \% of certain $\alpha$-phase alumina particulate fillers [7-20]. As the mysterious synergistic mechanisms for this wear reduction have been more recently uncovered, the importance of tribochemistry $[8,10-12,17$, 21], tribofilm formation [9, 18-20, 22], multi-scale mechanics [13, 17, 23], environmental and sliding conditions $[8,10,12]$, countersample roughness [16, 24, 25] and numerous other system phenomena/parameters has been highlighted.

However, one disadvantage of PTFE is its manufacturability. PTFE has near infinite melt viscosity (near zero melt flow rate) [26] which prevents the use of screw injection molding. Thus, PTFE parts are typically manufactured using compression molding and sintering, which can only create simple geometries. Complex geometries must be machined after the part has been sintered, which adds additional cost to the manufacturing process. However, perfluroalkoxy polymer (PFA) is a perfluoropolymer with properties similar to PTFE, but with a higher melt flow rate $(\sim 14 \mathrm{~g} / 10 \mathrm{~min})$ [26]. PFAs are a group of copolymers of TFE with small amounts of various types of perfluoroalkylvinyl ethers (alkyl = methyl [PMVE], ethyl [PEVE], propyl [PPVE]) which along with a chain transfer agent, decrease the molecular weight and increase the melt flow rate enough to enable injection molding (see Figure 1 for chemical structure) [27]. PFA has a larger coefficient of friction than PTFE but it is lower than many bulk polymers and can be used at a great range of operating temperatures [28, 29].

\subsection{Review of PTFE and filled PTFE Composite Wear Mechanisms}

Under typical engineering sliding speeds and loads, wear rates of PTFE are often very high (as much as $1 \times 10^{-3} \mathrm{~mm}^{3} / \mathrm{Nm}$ ). Tanaka mapped out the wear of PTFE as a function of temperature and sliding speed, reporting a transition in wear rate that suggests a threshold between multiple wear mechanisms of PTFE [30]. Tanaka proposed that the banded structure of PTFE is responsible for this large scale, flakey wear debris and compared it to a deck of cards [31, 32]. At lower sliding speeds and contact pressures, the wear of PTFE is extremely low. Studies by Blanchet and Kennedy suggested that at higher sliding speeds, delamination wear was initiated due to the kinetic friction coefficient reaching a threshold [3]. At this threshold, subsurface shearing of the polymer became preferential as the shear stress at the internal interfaces of the PTFE became lower than the shear stress at the interface. This process led to subsurface crack propagation, joining, and delamination wear [33].

A wide variety of materials have been included as filler materials in PTFE [3-5, 14, 34-42]. Most serve to moderately reduce wear (by one or two orders of magnitude) while increasing friction. Several hypotheses exist as to why fillers reduce the wear of PTFE. Preferential load support [34, 43] and arresting crack propagation [3, 37] are among the two most popular theories. Blanchet and Kennedy proposed that fillers serve to shut down the delamination wear of PTFE [44]. Through experiments with high density and low density polyethylene, Briscoe proposed that fillers promote the generation of thin, well adhered transfer films that reduce wear by slowing the removal and subsequent replacement of transfer films [35]. For nanoparticle filled systems that produce low wear at low filler percent, Li et al. agreed with the theory of Briscoe that thin, robust, well-adhered transfer films bond to the counter sample and protect the sample 
from further wear $[35,40]$. Others suggest that nanoparticles prevent the crystalline structure of the PTFE from being destroyed during sliding [41].

\subsection{Review of Ultralow Wear PTFE/alumina Composite Wear Mechanisms}

For over a decade, composites of PTFE containing low concentrations ( $<5 \mathrm{vol} \%)$ of certain special alpha-phase alumina particles have been studied due to their wear rates that are four orders of magnitude lower than unfilled PTFE [7-9, 13, 14, 16-18, 45-49]. Mechanistic theories based on both experiments and modeling have indicated the importance of transfer films [8, 9, $16,18,45,47]$, running films on the wear surface of the polymer [17, 47], polymer morphology [14, 45, 49, 50], filler phase, size and shape [7, 13, 16, 50], composite dispersion [14], filler reinforcement mechanisms $[17,50]$, PTFE fibrillation $[49,50]$, environmental chemistry $[8,10]$ and countersurface roughness $[16,24]$. It is difficult to directly rule out many of the previously presented theories because there are multiple length-scale and time-scale, physical, mechanical, chemical and material dominated phenomena occurring in concert to result in the "ultralow" wear behavior of these composites. Most mechanistic theories for wear reduction in PTFE rely on the transfer of polymeric material from the surface of the composite to the surface of a countersample (steel for many prior studies) [9]. PTFE has been shown to transfer to a metal countersample after only a single sliding cycle [51, 52]. During these transfer events, carboncarbon bonds are broken, presenting an opportunity for tribochemistry $[5,6,8,11,17,46,47$, 51-60].

Recently, the mechanism behind this remarkable material has been investigated using various research tools including XPS, FTIR, AFM, nano-indentation, 3D X-ray microtomography, and environmental/vacuum testing $[8-12,17]$. Harris et al. explained that the chemical signature of the transfer films and running films was consistent with newly formed carboxylate end groups [11]. They showed that these endgroups arose by a two-step process: first, carbon radicals were formed by mechanochemical breaking of C-C bonds in the PTFE backbone, followed by reaction with oxygen and water from the ambient environment. These new endgroups were shown to chelate to both the metal countersurface to form a tenacious transfer film, and to the alumina filler surface, thereby effectively crosslinking the polymer matrix [11].

\subsection{Preliminary Hypothesis}

Although PFA has been around since the early 1970s, its tribological properties have rarely been evaluated [61], especially compared to PTFE and PTFE composites. Considering PFA's random copolymer structure of mostly TFE and a small fraction of PPVE monomer, the ultralow wear mechanism for PTFE- $\alpha$ alumina composites described above would still apply to PFA- $\alpha$ alumina composites. The tribochemical mechanisms explained by Harris et al. would still occur due to similar mechanical stresses causing chain scission along the carbon backbone of the PFA molecular chain. This chain scission would still lead to the formation of carbon radicals, which would likely bond with water and oxygen from the environment. These endgroups would still likely chelate to the metallic countersurface and the alumina particles on the surface of the PFA$\alpha$ alumina composites. To evaluate this hypothesis, the tribological properties of both unfilled PFA 340 and PFA 340- $\alpha$ alumina composites were investigated as well as the chemical spectra of their tribofilms. 


\section{Materials and Sample Preparation}

Blends of DuPont (now Chemours) Teflon ${ }^{\circledR}$ PFA 340 (TFE-co-PPVE) and $\alpha$-alumina were prepared using a ZSK $18 \mathrm{~mm}$ co-rotating twin screw megacompounder with a typical screw design for dispersion of inorganics in fluorinated materials. Alumina contents ranging from 0 to 10 wt. $\%$ were studied. The alumina was dried for 8 hours at $100{ }^{\circ} \mathrm{C}$ prior to compounding; PFA pellets were used as received. The alumina filler was added to the primary extruder feed along with the PFA. The resulting strand was water quenched and pelletized. These pellets were dried and then used to mold 40 × 40 × $7.5 \mathrm{~mm}$ plaques using a Boy Machines $22 \mathrm{AV}$ single screw vertical barrel, vertical platen injection molding machine. When injection molding these parts from PFA, optimal part strength was obtained by allowing the parts to cool slowly in a relatively hot mold; in this case, the initial mold temperature was $285{ }^{\circ} \mathrm{C}$ and cooling times were approximately 40 seconds. The $\alpha$-alumina "nanoparticles" were purchased from Nanostructured and Amorphous materials, Stock \# 1015WW. As previously published [23] these particles were shown to be micron sized porous agglomerates with a $\mathrm{D}_{50}=3.95 \mu \mathrm{m}$ by static light scattering and a BET surface area of $41.4 \mathrm{~m}^{2} / \mathrm{g}$.

After the part was removed from the injection mold cavity, the $6.3 \mathrm{~mm} \times 6.3 \mathrm{~mm} \times 12.7 \mathrm{~mm}$ polymer were machined for use in wear testing. The surface to be tested was polished using a polishing wheel with 800 grit $\mathrm{SiC}$ sandpaper. The test samples were then placed in a methanol bath and sonicated for thirty minutes to ensure any contaminants on the surface of the samples had been removed. The polymer samples were removed from the bath and allowed to dry for at least four hours in laboratory air before testing began. 304L stainless steel with a lapped surface finish $(\mathrm{Ra} \sim 150 \mathrm{~nm})$ was chosen as the countersurface for this study (prepared by Metal Samples Co.). The countersamples were washed with Softsoap ${ }^{\circledR}$ (Colgate-Palmolive Company) and tap water and then rinsed with methanol at least thirty minutes before testing started.

\section{Experimental Methods}

\subsection{Tribometer}

A linear reciprocating tribometer as previously described [62] was used to perform the lab tests. Temperature and relative humidity of the laboratory air were monitored during all tests. Normal and frictional forces applied to the polymer pin were monitored using a six axis load cell (AMTI MC3A-1000, Watertown MA). A linear ball motor stage reciprocated the countersample across the pin surface. Control of the pneumatic thruster, linear stage, and data acquisition was performed by LabVIEW ${ }^{\circledR}$ (National Instruments, Austin TX). Uncertainties in friction coefficient reported are less than 0.005 [62]; this uncertainty is much lower than the statistical variation in friction coefficient.

\subsection{Wear Rate Measurement}

Wear rate was quantified on a mass/density basis (Eq. 1). The sample dimensions were measured using calipers before testing (nominally $6.35 \times 6.35 \times 12.7 \mathrm{~mm}$ with small variations from machining). Its mass was recorded using a balance with a $0.01 \mathrm{mg}$ resolution. From this initial measurement the density of the polymer was determined (nominally $2.15 \mathrm{~g} / \mathrm{cm}^{3}$ ). Wear rate of the polymer $(K)$ was calculated using Archard's wear law [63], which defines wear rate as volume lost $\left(V_{\text {lost }}\right)$ of the material divided by an applied normal load $\left(F_{n}\right)$ and sliding distance $(d)$. This is rewritten in terms of change in mass caused by wear $(\Delta m)$ and density $(\rho)$ (Eq. 1) 


$$
K=\frac{V_{\text {lost }}}{F_{n} \cdot d}=\frac{\Delta m / \rho}{F_{n} \cdot d}
$$

Mass measurements of the polymer were taken incrementally to evaluate wear rate as a function of sliding cycles. The number of cycles between massing increased with increasing sliding cycles to resolve transient wear of early cycles (run-in) from steady-state wear rate at extended sliding cycles.

\subsection{Experiments}

A normal load of $250 \mathrm{~N}$ (6.3 MPa) was used as a direct comparison to many PTFE- $\alpha$ alumina composite systems that have been previously tested. A sliding speed of $50.8 \mathrm{~mm} / \mathrm{s}$ and a sliding stroke of $25.4 \mathrm{~mm}$ were used to simulate typical engineering conditions and previous studies on PTFE systems [8-12, 17-20,46]. Tests were run until the polymer pin failed due to excessive wear (greater than $50 \mathrm{~mm}^{3}$ ) or until half a million sliding cycles $(25.4 \mathrm{~km}$ of sliding) were completed.

\subsection{Infrared Spectroscopy}

Recent papers $[8,11,19,23]$ have demonstrated the importance of tribochemistry in creating ultralow wear fluoropolymer composite systems. Multiple types of spectroscopy have shown that chemical endgroups on the metallic countersample and running surface of the polymer composite films are critical for PTFE- $\alpha$ alumina composites to achieve ultralow wear conditions. Infrared spectra of the running surface of the polymer pin and the bulk surface of the polymer were taken using attenuated total reflectance infrared (ATR-IR) with a Golden Gate (Specac) horizontal diamond ATR. Infrared spectra of the polymeric PFA transfer films on the metal countersample were acquired using a Thermo Scientific Nicolet Continu $\mu$ m infrared microscope (Thermofisher Scientific) in reflectance mode. The size of the transfer film area that was analyzed was governed by the $100 \mu \mathrm{m}$ aperture used.

\section{Results and Discussion}

\subsection{Tribological behavior}

The friction coefficient versus sliding distance for the unfilled PFA and PTFE samples is shown in Figure 2. The initial friction coefficient (average over first 1,000 cycles) for unfilled PFA 340 was 0.29 and it slowly decreased over time to a final value of 0.24 . This was significantly higher than the value of unfilled PTFE $(\mu \sim 0.14)$. The reason for this difference in friction has been assigned to the perfluoroethoxy $\left(\mathrm{C}_{2} \mathrm{~F}_{5} \mathrm{O}-\right)$ sidegroups in PFA 340 disrupting the smooth molecular profile of the linear fluoropolymer [29, 64].

The initial friction coefficient (average over first 1,000 cycles) of PFA- $\alpha$ alumina composites ranged between $0.20-0.24$, then followed a moderate decrease in friction coefficient during the first $250 \mathrm{~m}$ of sliding ( $\mu \sim 0.16-0.21$ ) (Figure $3 \mathrm{~b}$ ). This drop in friction coefficient was followed by an increase in friction coefficient up to 0.24-0.27 during the last $15 \mathrm{~km}$ of sliding (Figure $3 \mathrm{a}$ ). Friction coefficient for PTFE- $\alpha$ alumina composite was initially very low, $(\mu \sim 0.16-0.18)$, during the first $250 \mathrm{~m}$ of sliding (Figure 3a-b). After that initial $250 \mathrm{~m}$ of sliding, the PTFE- $\alpha$ alumina composite followed a similar trend of increasing friction coefficient with increasing sliding distance seen in the PFA composites resulting in a final friction coefficient of 0.26 . After the initial run-in period, the friction coefficient of PTFE and PFA alumina composites is comparable which is surprising due to the significantly higher friction coefficient of unfilled PFA compared to unfilled PTFE. This shows that the tribochemically-generated transfer films and running films 
for PFA- $\alpha$ alumina composites are not that different from PTFE- $\alpha$ alumina composites (this is supported below by IR spectroscopy).

The wear behavior of PFA and PFA- $\alpha$ alumina composites is exhibited using volume lost versus sliding distance graphs (Figure 4). Figure 4a illustrates the drastic improvement in wear rate achieved by adding 5-10 wt. \% alumina to PFA. The final wear rate of unfilled PFA ranged between $1.4-6.7 \times 10^{-4} \mathrm{~mm}^{3} / \mathrm{Nm}$ and PFA- $\alpha$ alumina composites were found to be $6.8 \times 10^{-8}$ $\mathrm{mm}^{3} / \mathrm{Nm}(5$ wt. $\%), 4.0 \times 10^{-8} \mathrm{~mm}^{3} / \mathrm{Nm}\left(7.5\right.$ wt. \%) and $4.3 \times 10^{-8} \mathrm{~mm}^{3} / \mathrm{Nm}(10 \mathrm{wt} . \%), \sim 10,000$ times better than unfilled PFA (Figure 4). The volume loss curves show that the initial wear rate of the PFA- $\alpha$ alumina composites was quite high (first 1000 sliding cycles $(50.8 \mathrm{~m})$ ) (Figure 4b); but, the composites then transitioned to an ultralow wear regime $\left(\mathrm{K}<1 \times 10^{-6} \mathrm{~mm}^{3} / \mathrm{Nm}\right)$ after 2,500m (Figure 4c).

This extraordinary decrease in wear rate was similar to that seen in PTFE- $\alpha$ alumina composites $[8,10-14,17,18,25]$, however this is the first time wear rates this low have been reported for a non-PTFE perfluoropolymer. A summary of the tribological tests completed for this study is shown in Table 1.

\subsection{Tribofilm morphology}

Like the PTFE- $\alpha$ alumina composite system, the worn surface of the PFA- $\alpha$ alumina composites and the metallic surface it slid upon (i.e. the running film and transfer film respectively) show characteristic differences compared to unfilled samples [17]. The primary qualitative differences between the unfilled PFA compared to filled PFA- $\alpha$ alumina composites are the brown films on the surface of the PFA- $\alpha$ alumina composite surface/metallic countersurface pair as well as a change in the shape and size of the wear debris (Figure 5). For the unfilled PFA running film, there is no noticeable change in color during the test duration (10,000 cycles). At the end of the sliding stroke on the stainless steel countersurface, the unfilled PFA produced a large amount of string-like wear debris (different from the flaky wear debris seen in unfilled PTFE $[3,6])$. The brown color associated with ultralow wear PTFE- $\alpha$ alumina composites after a thousand cycles on the sliding surface of the polymer was also observed in PFA- $\alpha$ alumina composites [17]. These running films dull during the course of testing as shown by the running films after $25.4 \mathrm{~km}$ of sliding.

The transfer film on the stainless steel surface was usually clear with a few brown regions and particulates that accumulated at the ends of the transfer film (Figure 6). These wear debris were much smaller in size than the corresponding unfilled counterparts. The difference in the quantity of wear debris produced in the filled versus unfilled PFA was quite startling, especially because the PFA- $\alpha$ alumina composites pin ran for 50 times longer and exhibited only a small fraction of wear debris compared to the unfilled sample.

\subsection{Infrared Spectroscopy of Tribofilms}

IR spectra revealed large differences in the chemistry of tribofilms (schematically defined in Figure 7a) from PFA and PFA- $\alpha$ alumina composites. ATR-FTIR spectra were acquired on the unworn surface (Figure 7a) and the wear surface (running film) on the metal counterface (Figure $7 b$ ) of the PFA and PFA- $\alpha$ alumina composite. Unfilled PFA had nearly identical spectra for both worn and unworn surfaces, with characteristic peaks assigned to $-\mathrm{CF}_{2}$ - units of the backbone $\left(\sim 1148 \mathrm{~cm}^{-1}\right.$ and $\left.\sim 1204 \mathrm{~cm}^{-1}\right)$ as well as a peak at $993 \mathrm{~cm}^{-1}$ from the $-\mathrm{CF}_{3}$ group of the PPVE comonomer. Unworn PFA with 10 wt. \% alumina shared the primary peaks corresponding to the TFE and PPVE monomers in the fluoropolymer matrix, but also had an additional broad 
absorbance below $1000 \mathrm{~cm}^{-1}$ in the metal-oxo region corresponding to the alumina filler. New chemical species were observed in the spectra of worn PFA- $\alpha$ alumina running film, similar to those found in previously reported PTFE- $\alpha$ alumina tribofilms [9]. These include two broad C-O stretches of perfluorocarboxylate salts $\left(\sim 1434 \mathrm{~cm}^{-1}\right.$ and $\left.\sim 1665 \mathrm{~cm}^{-1}\right)$ and the broad $-\mathrm{OH}$ stretches from waters of hydration $\left(3265 \mathrm{~cm}^{-1}\right)$.

FTIR (in reflectance mode) of the $10 \mathrm{wt}$ \% alumina filled PFA transfer film showed peaks consistent with transfer of PFA to the steel surface: 1159,1216 , and $993 \mathrm{~cm}^{-1}$. There were also new broad peaks at 1439, 1686 and $3265 \mathrm{~cm}^{-1}$, corresponding to hydrated perfluorocarboxylate salts. Finally, the chemical signature of the aluminum oxide filler was again present (broad absorbance below $1000 \mathrm{~cm}^{-1}$ ).

\subsection{Mechanistic Discussion}

It was expected that alumina fillers would reduce the wear rate of PFA by several orders of magnitude, comparable to the well-documented reduction of wear in PTFE- $\alpha$ alumina composites. The wear rate of PFA was reduced by more than three orders of magnitude with the inclusion of 5-10 wt. \% alumina filler. The characteristic morphological and chemical changes linked to the ultralow wear performance of PTFE- $\alpha$ alumina composites were also observed in PFA- $\alpha$ alumina composites. The carboxylate salts observed in the running film and transfer film of PFA- $\alpha$ alumina composites were consistent with the hypothesized mechanism that included tribochemical breaking of $\mathrm{C}-\mathrm{C}$ bonds along the fluoropolymer backbone. This is followed by the reaction of carbon radicals and environmental species, resulting in the formation of new endgroups (carboxylic acids) which can subsequently chelate to metals and metal oxides, forming well adhered transfer films (through substrate-polymer chelations) as well as mechanically reinforced tribofilms (from multiple carboxyl endgroup chelations to the same metallic/metal oxide particle, essentially forming a crosslinked fluoropolymer surface). This extends the conceptual framework for wear of PTFE- $\alpha$-alumina composites to wear of other perfluoropolymer/alumina composite systems.

\section{Conclusions}

The addition of 5-10wt. \% $\alpha$ alumina to PFA 340 polymer achieved ultra-low wear rates that were nearly 10,000x less than unfilled PFA 340 at $6.25 \mathrm{MPa}$ of applied pressure. Frictional behavior of the $\alpha$ alumina-filled PFA composite was comparable to unfilled PFA and $\alpha$ alumina filled PTFE. The reduction in wear corresponded to the development of tribofilms at the sliding interface. A dark brown running film was seen in PFA 340-alumina composites after 1,000 cycles that dulled in color with increasing cycles, (no brown coloring was seen on the unfilled PFA 340 sample). Transfer films on the steel countersurfaces slid against the filled PFA 340alumina showed a slight brown color. Wear debris produced by the PFA- $\alpha$ alumina composites was much smaller and darker than the large flakey debris found in unfilled PFA.

Infrared spectroscopy of the tribofilms of PFA- $\alpha$ alumina composites revealed chemical groups that were not present in the unfilled PFA sample's tribofilms. The chemical endgroups present in the tribofilms of the $\alpha$ alumina filled PFA samples include carboxylate groups which are hypothesized to form from the ends of mechanically broken PFA chains and environmental constituents. These carboxylates chelate to metal/metal oxides on the surface of the polymer and countersample to form robust, protective transfer films. This mechanism extends the framework 
for ultra-low wear PTFE- $\alpha$ alumina composites, which similarly relies on tribochemical reactions at the sliding interface to produce robust tribofilms.

\section{Acknowledgements}

This material is based upon work supported by the National Science Foundation under Grant No. 1463141.

The authors would like to thank John Curry and Guosong Zeng of the Lehigh Tribology Laboratory for their help with the experiments. The authors would like to thank Dick Towne and Eli Towne of the Lehigh Mechanical Engineering and Mechanics Department Staff for their help building the linear reciprocating tribometer and their machining advice to the students of the Lehigh Tribology lab. 


\section{Figures and Figure Captions}

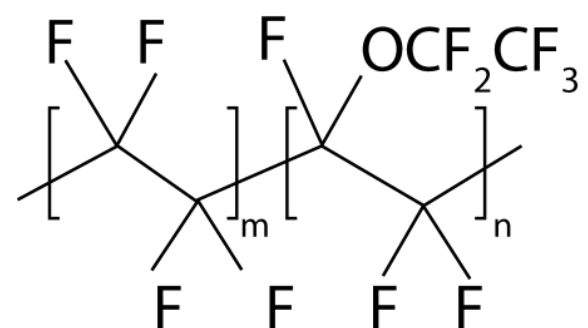

Figure 1: Chemours ${ }^{\circledR}$ Perfluoroalkoxy Polymer (PFA) molecular structure.



Figure 2: Friction coefficient versus sliding distance of unfilled PFA 340 and unfilled PTFE

(a)

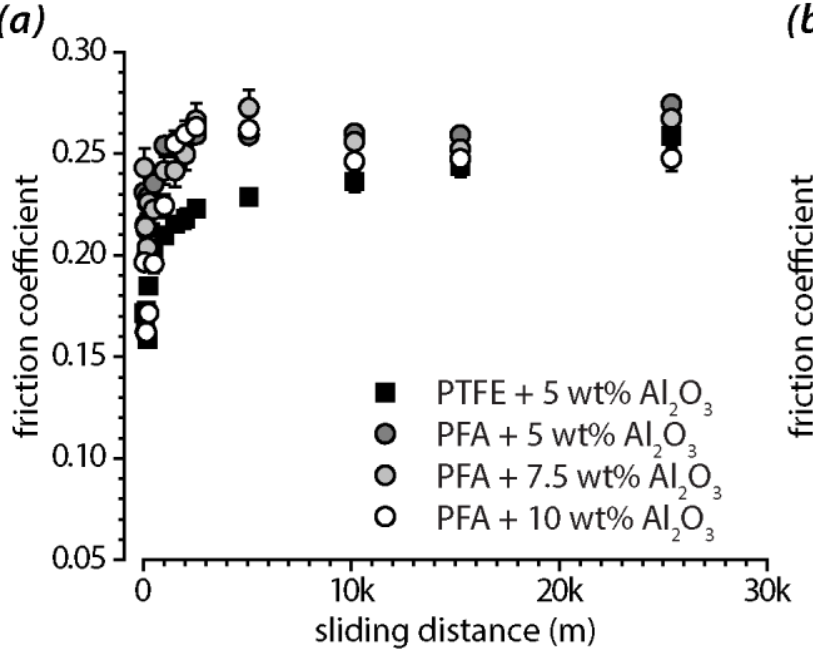

(b)

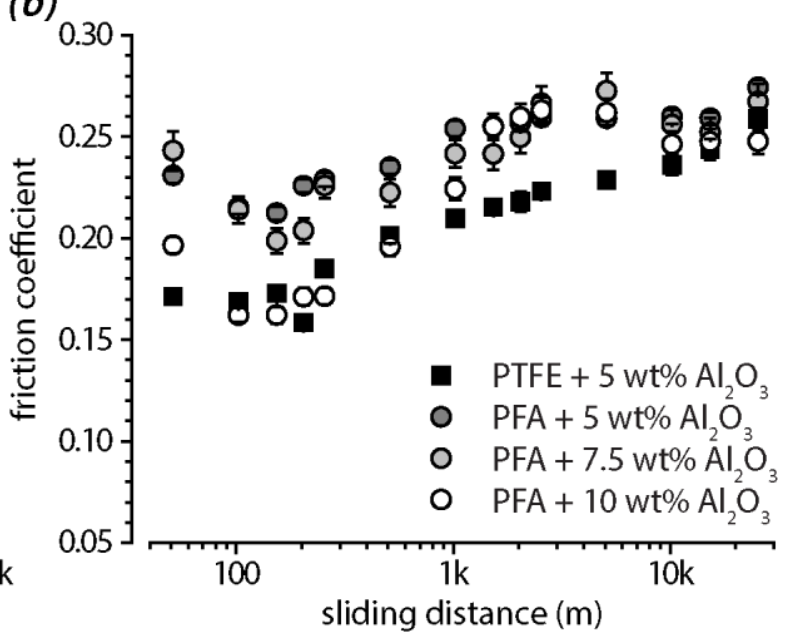

Figure 3: Friction coefficient versus sliding distance of PFA 340 with 5.0, 7.5, and 10.0 wt. \% alumina, and PTFE with 5 wt. \% alumina on linear (a) and semi-log (b) scales. 


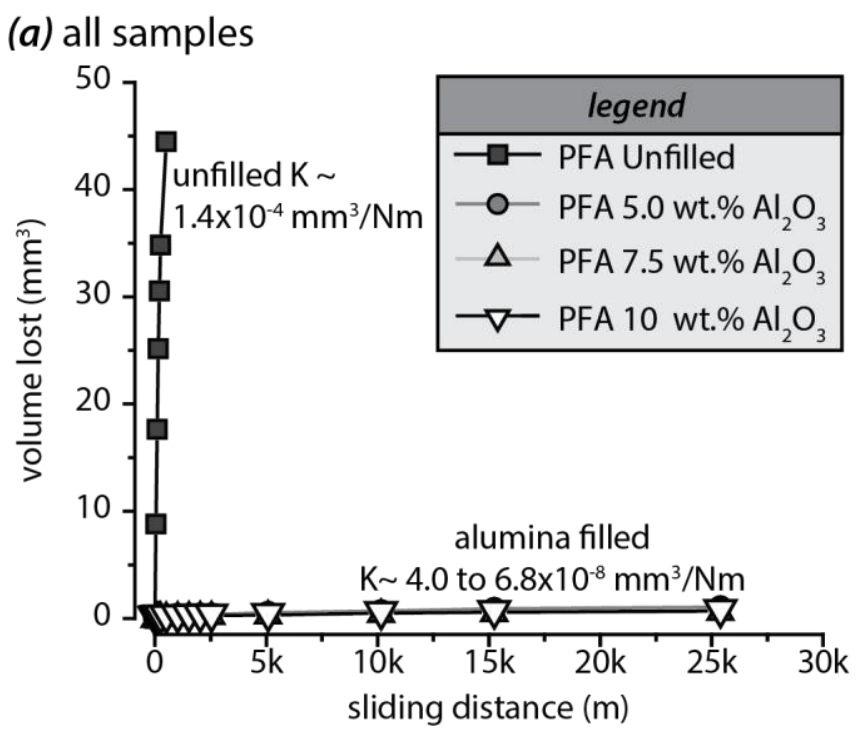

(b) filled samples: first 50,000 cycles (2,540 meters



(c) filled samples: 500,000 cycles $(25,400 \mathrm{~m})$




Figure 4: (a) Volume lost versus sliding distance for PFA and PFA alumina composites. (b) Volume lost versus sliding distance for first $\mathbf{5 0 , 0 0 0}$ sliding cycles (to visualize run-in). (c) Volume lost versus sliding distance for entire 500,000 sliding cycle experiment. 


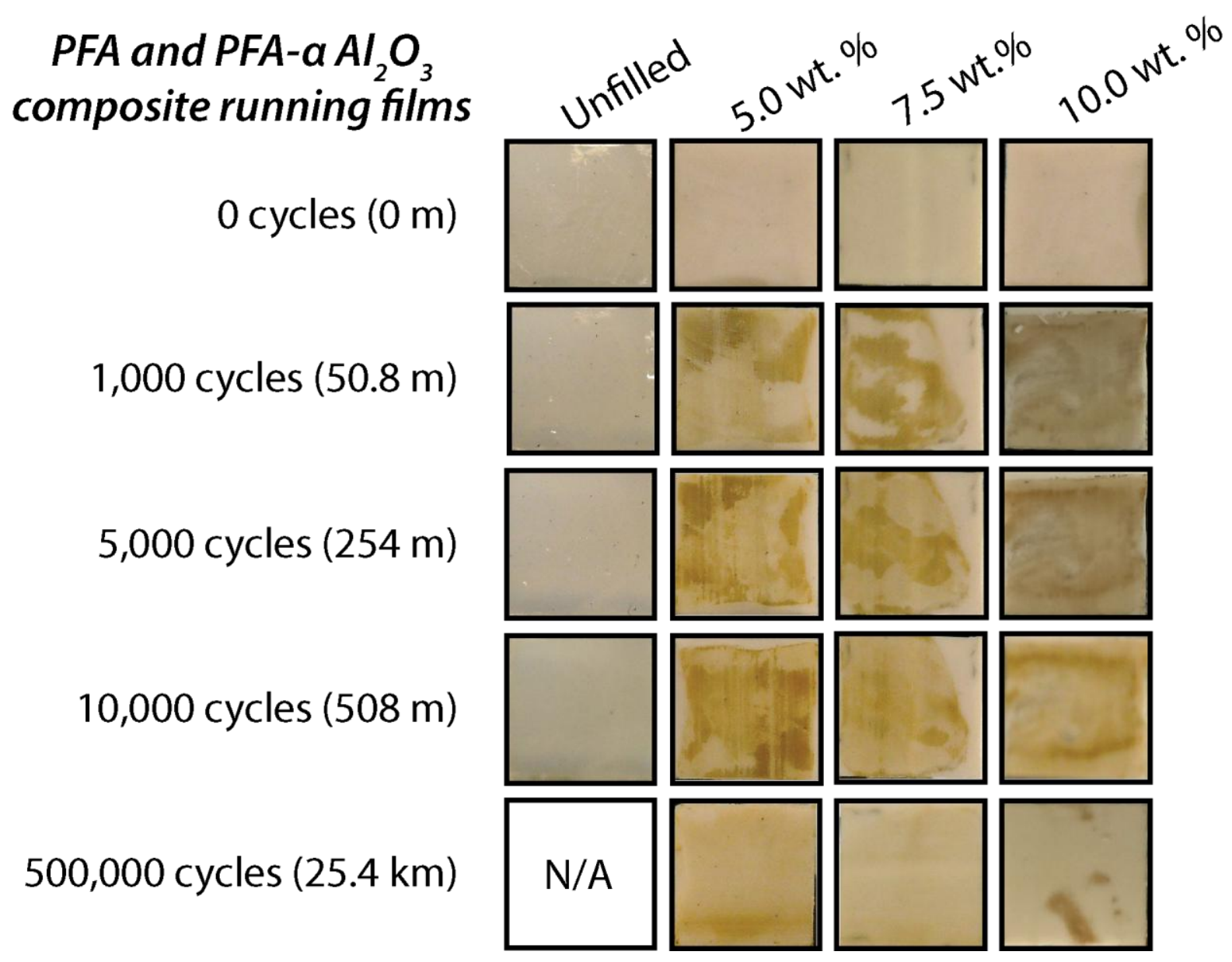

Figure 5: Running film evolutions for PFA and PFA $\alpha$-alumina composites after $25.4 \mathrm{~km}$ of sliding. Periodic photographs of wear surface of the polymer/polymer composites. 


\section{transfer films for PFA and PFA alumina composites}

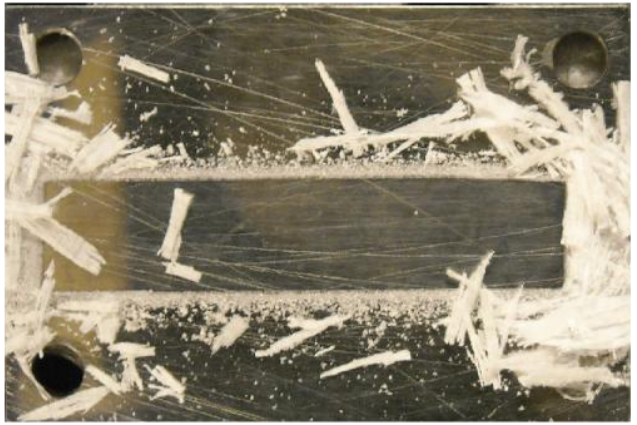

Unfilled PFA after 10,000 cycles

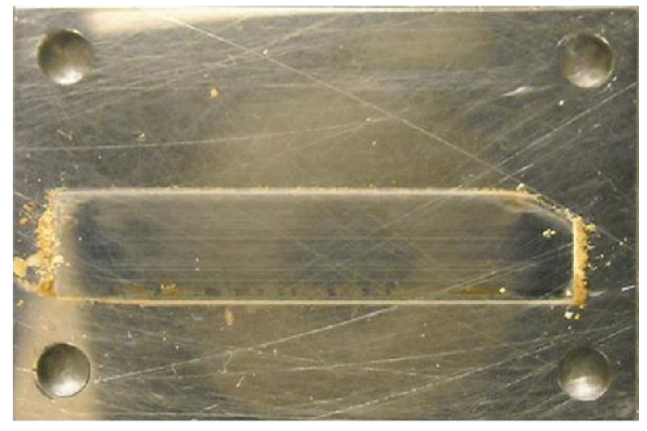

PFA with 7.5 wt. $\% \mathrm{Al}_{2} \mathrm{O}_{3}$ after 500,000 cycles

Figure 6: Transfer films of PFA unfilled after $508 \mathrm{~m}$ of sliding and 7.5 weight percent $\alpha$ alumina after $25.4 \mathrm{~km}$ of sliding. 
(a) ATR-FTIR of polymer surfaces



(b) FTIR of PFA/alumina transfer film

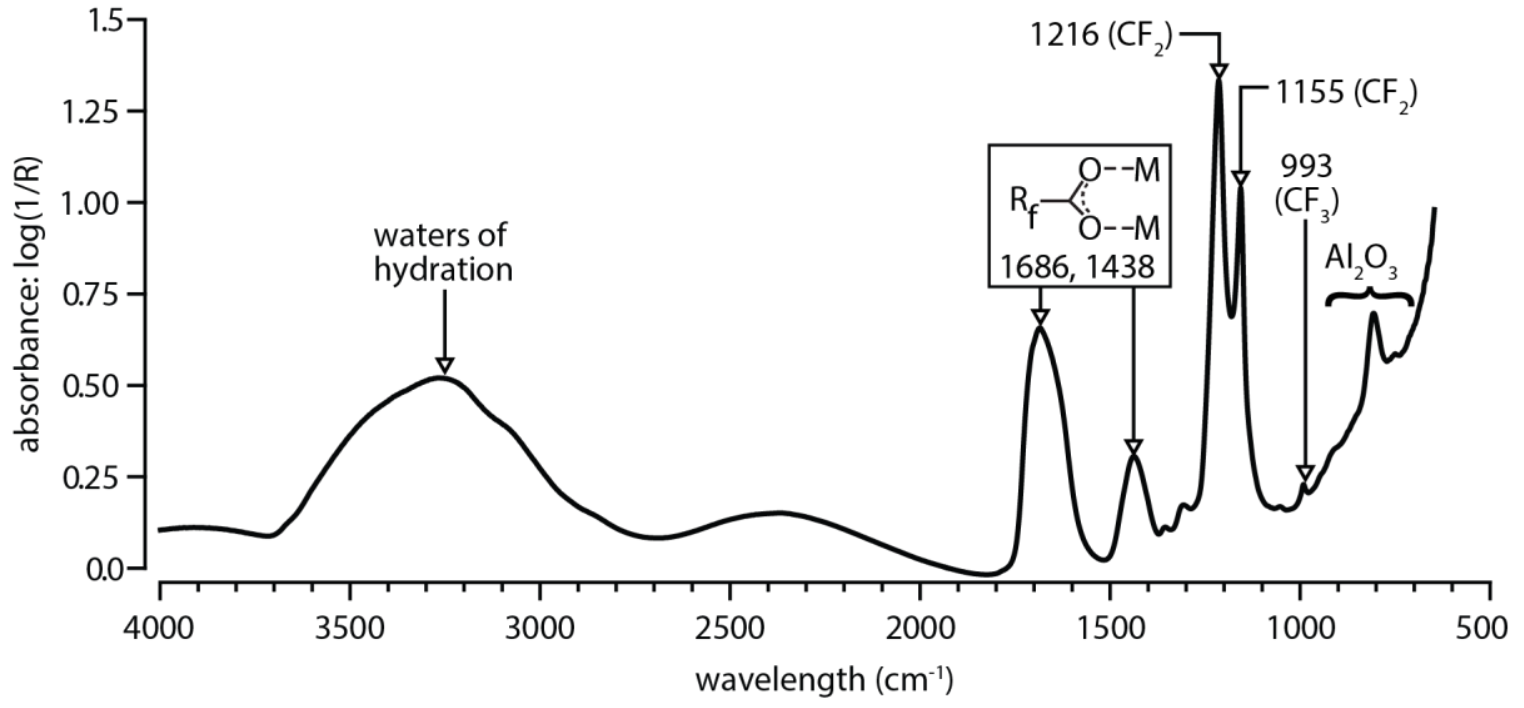

Figure 7: (a) ATR spectra of bulk and worn surfaces of PFA unfilled and PFA with 10wt. \% $\mathrm{Al}_{2} \mathrm{O}_{3}$. Note that the chemical differences are only truly noticeable between the worn PFA composite surface. All other surfaces tested have nearly identical chemical spectra. (b) FTIR spectrum of transfer film formed from sliding PFA with $10 \mathrm{wt} . \% \mathrm{Al}_{2} \mathrm{O}_{3}$ on 304 stainless steel countersample. 
Tables and Table Captions

\begin{tabular}{|c|c|c|c|c|c|c|}
\hline wt. $\% \mathrm{Al}_{2} \mathrm{O}_{3}$ & $\begin{array}{c}\mathrm{K}_{\text {initial }} \\
\left(\mathrm{mm}^{3} / \mathrm{Nm}\right)\end{array}$ & $\begin{array}{c}\mathrm{K}_{\text {final }} \\
\left(\mathrm{mm}^{3} / \mathrm{Nm}\right)\end{array}$ & $\mu_{\text {initial }}$ & $\mu_{\text {final }}$ & $\mathrm{RH}(\%)$ & $\begin{array}{c}\text { RH STD } \\
\mathrm{DEV} \\
(\%)\end{array}$ \\
\hline Unfilled PFA & $6.6 \times 10^{-4}$ & $1.4 \times 10^{-4}$ & 0.29 & 0.24 & 26 & 0.6 \\
\hline $5.0(\mathrm{PTFE})$ & $6.9 \times 10^{-6}$ & $4.4 \times 10^{-8}$ & 0.17 & 0.26 & 19 & 1.0 \\
\hline 5.0 & $1.7 \times 10^{-5}$ & $6.8 \times 10^{-8}$ & 0.23 & 0.27 & 28 & 3.6 \\
\hline 7.5$]$ & $1.0 \times 10^{-5}$ & $4.0 \times 10^{-8}$ & 0.24 & 0.27 & 13 & 2.5 \\
\hline 10.0 & $9.4 \times 10^{-6}$ & $4.3 \times 10^{-8}$ & 0.20 & 0.25 & 12 & 1.4 \\
\hline
\end{tabular}

Table 1: Initial and final wear rates and friction coefficients $(\mu)$ for various weight percentages of $\mathrm{Al}_{2} \mathrm{O}_{3}$ in PFA and PTFE composites tested. $\mathrm{K}_{\text {initial }}$ is the mass based wear rate after 1,000 sliding cycles. $K_{\text {final }}$ is the final differential mass-based wear rate: for unfilled polymers this is the final 5,000 sliding cycles (from 5,000 to 10,000 total cycles); for filled polymers this is the final 200,000 sliding cycles (from 300,000 to 500,000 total cycles). $\mu_{\text {initial }}$ is the average friction coefficient over first 1,000 cycles and $\mu_{\text {final }}$ is the average friction coefficient for the last experiment (ie 5,000 to 10,000 total cycles for unfilled and 300,000 to 500,000 total cycles for filled). 


\section{References}

1. Unlu, B.S., Atik, E., Koksal, S.: Tribological properties of polymer-based journal bearings. Mater. Des. 30, 2618-2622 (2009).

2. Tevrüz, T.: Tribological behaviours of bronze-filled polytetrafluoroethylene dry journal bearings. Wear. 230, 61-69 (1999).

3. Blanchet, T.A., Kennedy, F.E.: Sliding wear mechanism of polytetrafluoroethylene (PTFE) and PTFE composites. Wear. 153, 229-243 (1992).

4. Uchiyama, Y., Tanaka, K.: Wear laws for polytetrafluoroethylene. Wear. 58, 223-235 (1980).

5. De-Li, G., Bing, Z., Qun-Ji, X., Hong-Li, W.: Effect of tribochemical reaction of polytetrafluoroethylene transferred film with substrates on its wear behaviour. Wear. 137, 267-273 (1990).

6. Biswas, S.., Vijayan, K.: Friction and wear of PTFE - a review. Wear. 158, 193-211 (1992).

7. Burris, D.L., Sawyer, W.G.: Improved wear resistance in alumina-PTFE nanocomposites with irregular shaped nanoparticles. Wear. 260, 915-918 (2006).

8. Krick, B.A., Ewin, J.J., Blackman, G.S., Junk, C.P., Sawyer, W.G.: Environmental dependence of ultra-low wear behavior of polytetrafluoroethylene (PTFE) and alumina composites suggests tribochemical mechanisms. Tribol. Int. 51, 42-46 (2012).

9. Ye, J., Khare, H.S., Burris, D.L.: Transfer film evolution and its role in promoting ultralow wear of a PTFE nanocomposite. Wear. 297, 1095-1102 (2013).

10. Pitenis, A.A., Ewin, J.J., Harris, K.L., Sawyer, W.G., Krick, B.A.: In vacuo tribological behavior of polytetrafluoroethylene ( $\mathrm{ptfe}$ ) and alumina nanocomposites: The importance of water for ultralow wear. Tribol. Lett. 53, 189-197 (2014).

11. Harris, K.L., Pitenis, A.A., Sawyer, W.G., Krick, B.A., Blackman, G.S., Kasprzak, D.J., Junk, C.P.: PTFE Tribology and the Role of Mechanochemistry in the Development of Protective Surface Films. Macromolecules. 150526153713007 (2015).

12. Khare, H.S., Moore, A.C., Haidar, D.R., Gong, L., Ye, J., Rabolt, J.F., Burris, D.L.: Interrelated Effects of Temperature and Environment on Wear and Tribochemistry of an Ultralow Wear PTFE Composite. J. Phys. Chem. C. 119, 16518-16527 (2015).

13. McElwain, S.E., Blanchet, T.A., Schadler, L.S., Sawyer, W.G.: Effect of Particle Size on the Wear Resistance of Alumina-Filled PTFE Micro- and Nanocomposites. Tribol. Trans. 51, 247-253 (2008).

14. Burris, D.L., Zhao, S., Duncan, R., Lowitz, J., Perry, S.S., Schadler, L.S., Sawyer, W.G.: A route to wear resistant PTFE via trace loadings of functionalized nanofillers. Wear. 267, 653-660 (2009).

15. Khare, H.S., Burris, D.L.: A quantitative method for measuring nanocomposite dispersion. Polymer (Guildf). 51, 719-729 (2010).

16. Blanchet, T.A., Kandanur, S.S., Schadler, L.S.: Coupled effect of filler content and countersurface roughness on PTFE nanocomposite wear resistance. Tribol. Lett. 40, 11-21 (2010). 
17. Krick, B.A., Ewin, J.J., McCumiskey, E.J.: Tribofilm Formation and Run-In Behavior in Ultra-Low Wearing Polytetrafluoroethylene (PTFE) and Alumina Nanocomposites. Tribol. Trans. 00-00 (2014).

18. Ye, J., Khare, H.S., Burris, D.L.: Quantitative characterization of solid lubricant transfer film quality. Wear. 316, 133-143 (2014).

19. Ye, J., Moore, A.C., Burris, D.L.: Transfer Film Tenacity: A Case Study Using UltraLow-Wear Alumina-PTFE. Tribol. Lett. 59, 50 (2015).

20. Urueña, J.M., Pitenis, A.A., Harris, K.L., Sawyer, W.G.: Evolution and Wear of Fluoropolymer Transfer Films. Tribol. Lett. 57, (2015).

21. Onodera, T., Kawasaki, K., Nakakawaji, T., Higuchi, Y., Ozawa, N., Kurihara, K., Kubo, M.: Chemical reaction mechanism of polytetrafluoroethylene on aluminum surface under friction condition. J. Phys. Chem. C. 118, 5390-5396 (2014).

22. Ye, J., Burris, D., Xie, T.: A Review of Transfer Films and Their Role in Ultra-Low-Wear Sliding of Polymers. Lubricants. 4, 4 (2016).

23. Krick, B.A., Pitenis, A.A., Harris, K.L., Junk, C.P., Sawyer, W.G., Brown, S.C., Rosenfeld, H.D., Kasprzak, D.J., Johnson, R.S., Chan, C.D., Blackman, G.S.: Ultralow Wear Fluoropolymer Composites: Nanoscale Functionality from Microscale Fillers. Tribol. Int. (2015).

24. Burris, D.L., Sawyer, W.G.: Tribological Sensitivity of PTFE/Alumina Nanocomposites to a Range of Traditional Surface Finishes. Tribol. Trans. 48, 147-153 (2005).

25. Harris, K.L., Curry, J.F., Pitenis, A.A., Rowe, K.G., Sidebottom, M. a., Sawyer, W.G., Krick, B.A.: Wear Debris Mobility, Aligned Surface Roughness, and the Low Wear Behavior of Filled Polytetrafluoroethylene. Tribol. Lett. 60, 2 (2015).

26. Gangal, S. V: Perfluorinated Polymers. In: Kirk-Othmer Encyclopedia of Chemical Technology. John Wiley \& Sons, Inc. (2004).

27. Ebhesajjad, S.: Fluoroplastics: Vol.2 Melt Processible Fluoropolymers: The Difinitive User's Guide and Databook. Plastics Design Library (2003).

28. Blanchet, T.A.: Friction,Wear, and PV Limits of Polymers and Their Composites. In: Booser, E.R. (ed.) Tribology Data Handbook. pp. 547-562. CRC Press, New York (1997).

29. Bowers, R.C., Zisman, W.A.: Frictional Properties of TetrafluoroethylenePerfluoro(propy1 vinyl ether) Copolymers. 13, 115-118 (1974).

30. Tanaka, K., Uchiyama, Y., Tooyooka, S.: The mechanism of wear of polytetrafluoroethylene above the melting point. Wear. 23, 153-172 (1973).

31. Bunn, C.: The fine structure of polytetrafluoroethylene. J. Polym. Sci. 28, 365-376 (1958).

32. Speerschneider, C.J., Li, C.H.: Some Observations on the Structure of Polytetrafluoroethylene. J. Appl. Phys. 33, 1871-1875 (1962).

33. Suh, N.P.: An overview of the delamination theory of wear. Wear. 21, 111-124 (1973).

34. Tanaka, K., Kawakami, S.: Effect of various fillers on the friction and wear of polytetrafluoroethylene-based composites. Wear. 79, 221-234 (1982). 
35. Briscoe, B.J., Pogosian, A.K., Tabor, D.: The friction and wear of high density polythene: The action of lead oxide and copper oxide fillers. Wear. 27, 19-34 (1974).

36. Clerico, M., Patierno, V.: Sliding wear of polymeric composites. Wear. 53, 279-301 (1979).

37. Nak-Ho, S., Suh, N.P.: Effect of fiber orientation on friction and wear of fiber reinforced polymeric composites. Wear. 53, 129-141 (1979).

38. Bahadur, S., Tabor, D.: The wear of filled polytetrafluoroethylene. Wear. 98, 1-13 (1984).

39. Briscoe, B.J., Lin Heng Yao, Stolarski, T. a.: The friction and wear of poly(tetrafluoroethylene)-poly (etheretherketone) composites: An initial appraisal of the optimum composition. Wear. 108, 357-374 (1986).

40. Li, F., Hu, K.A., Li, J.L., Zhao, B.Y.: The friction and wear characteristics of nanometer ZnO filled polytetrafluoroethylene. Wear. 249, 877-882 (2001).

41. Chen, W.X., Li, F., Han, G., Xia, J.B., Wang, L.Y., Tu, J.P., Xu, Z.D.: Tribological behavior of carbon-nanotube-filled PTFE composites. Tribol. Lett. 15, 275-278 (2003).

42. Sawyer, W.G., Freudenberg, K.D., Bhimaraj, P., Schadler, L.S.: A study on the friction and wear behavior of PTFE filled with alumina nanoparticles. Wear. 254, 573-580 (2003).

43. Lancaster, J.: Polymer-based bearing materials - role of fillers and fiber reinforcement in wear. Wear. 22, 412 (1972).

44. Blanchet, T.A., Kennedy, F.E.: A model for polymer composite wear behavior including preferential load support and surface accumulation of filler particulates. Tribol. Trans. 38, 821-828 (1995).

45. Burris, D.L., Boesl, B., Bourne, G.R., Sawyer, W.G.: Polymeric nanocomposites for tribological applications. Macromol. Mater. Eng. 292, 387-402 (2007).

46. Pitenis, A.A., Krick, B.A., Ewin, J.J., Harris, K.L., Sawyer, W.G.: In Vacuo Tribological Behavior of Polytetrafluoroethylene (PTFE) and Alumina Nanocomposites: The Importance of Water for Ultra-Low Wear. Tribol. Lett. 10.1007/s11249-013-0256-1 (2013).

47. Sawyer, W.G., Argibay, N., Burris, D.L., Krick, B.A.: Mechanistic Studies in Friction and Wear of Bulk Materials. Annu. Rev. Mater. Res. 44, 395-427 (2014).

48. Krick, B.A., Sawyer, W.G.: Space tribometers: design for exposed experiments on orbit. Tribol. Lett. 41, 303-311 (2011).

49. Kandanur, S.S., Schrameyer, M.A., Jung, K.F., Makowiec, M.E., Bhargava, S., Blanchet, T.A.: Effect of Activated Carbon and Various Other Nanoparticle Fillers on PTFE Wear. Tribol. Trans. 821-830 (2014).

50. Schadler, L.S., Brinson, L.C., Sawyer, W.G.: Polymer nanocomposites: A small part of the story. JOM. 59, 53-60 (2007).

51. Brainard, W.A., Buckley, D.H.: Adhesion and friction of PTFE in contact with metals as studied by Auger spectroscopy, field ion and scanning electron microscopy. Wear. 26, 7593 (1973).

52. Krick, B.A., Hahn, D.W., Sawyer, W.G.: Plasmonic Diagnostics for Tribology: In Situ 
Observations Using Surface Plasmon Resonance in Combination with Surface-Enhanced Raman Spectroscopy. Tribol. Lett. 49, 95-102 (2013).

53. Cadman, P., Gossedge, G.M.: The chemical nature of metal-polytetrafluoroethylene tribological interactions as studied by X-ray photoelectron spectroscopy. Wear. 54, 211215 (1979).

54. Jintang, G., Hongxin, D.: Molecule structure variations in friction of stainless steel/PTFE and its composite. J. Appl. Polym. Sci. 36, 73-85 (1988).

55. Deli, G., Bing, Z., Qun-Ji, X., Hong-Li, W.: Investigation of adhesion wear of filled polytetrafluoroethylene by ESCA, AES and XRD. Wear. 137, 25-39 (1990).

56. Deli, G., Qunji, X., Hong-Li, W.: ESCA study on tribochemical characteristics of filled PTFE. Wear. 148, 161-169 (1991).

57. Matsunuma, S.: The initial step of tribochemical reactions of perfluoropolyether on amorphous carbon. Wear. 213, 112-116 (1997).

58. Kajdas, C.K.: Importance of the triboemission process for tribochemical reaction. Tribol. Int. 38, 337-353 (2005).

59. Onodera, T., Park, M., Souma, K., Ozawa, N., Kubo, M.: Transfer-Film Formation Mechanism of Polytetrafluoroethylene: A Computational Chemistry Approach. J. Phys. Chem. C. 117, 10464-10472 (2013).

60. Przedlacki, M., Kajdas, C.K.: Tribochemistry of Fluorinated Fluids Hydroxyl Groups on Steel and Aluminum Surfaces. Tribol. Trans. 49, 202-214 (2006).

61. Crosby, J M , Theberge, J.E., Talley, K.L.: Melt Processible Fluropolymer Composites. J. Elastomers Plast. 13, 149-155 (1981).

62. Schmitz, T.L., Action, J.E., Burris, D.L., Ziegert, J.C., Sawyer, W.G.: Wear-Rate Uncertainty Analysis. J. Tribol. 126, 802 (2004).

63. Archard, J.F., Hirst, W.: The Wear of Metals under Unlubricated Conditions. Proc. R. Soc. A Math. Phys. Eng. Sci. 236, 397-410 (1956).

64. Pooley, C., Tabor, D.: Transfer of PTFE and Related Polymers in a Sliding Experiment. Nat. Phys. Sci. 237, 88-90 (1972). 